\title{
Shit euthanasie
}

\section{Artsen die in 2017 de Kaderopleiding Palliatieve Zorg volgden, schreven allen een kort verhaal over een palliatieve zorgervaring. Pallium publiceert een selectie daarvan. In dit nummer een bijdrage van Marjolein Steen.}

Alsof er op mijn voorhoofd geschreven staat: die dokter moet je hebben. Ik voelde het natuurlijk al aankomen, maar stak nog een paar dagen mijn kop in het zand. Heb ik dat: waarom hij, waarom ik, waarom nu? Shit. Shit. Shit.

Twee jaar geleden was het voor mij de eerste keer. Makkelijk toch: terminale kanker, levensverwachting nog een paar weken. Doe ik wel even; ik heb toch altijd het hoogste woord als het hierover gaat. Drie weken gaan er voorbij vanaf het eerste gesprek tot aan de bewuste dag. Ik vind toch dat euthanasie een groot goed is? En mijn leven ging, in tegenstelling tot het zijne, daarna ook gewoon door alsof er niets gebeurd was.

De tweede keer was anders. Mijn oudere, wijzere, zeer gewaardeerde collega kijkt me deze keer aan met een - hoe zal ik het omschrijven? - 'Lieve collega waar begin je aan, zou je dat wel doen, ik weet niet of $\mathrm{ik}$ het in dit geval zou kunnen-blik'. Ik bel zijn voormalige huisarts en die zegt: "Nee hoor, ik doe niet aan euthanasie." Shit. Shit. Shit.

En op een hele gewone dag besluit ik dat ik het doe. Ondanks de voor mij lastige opeenstapeling van somatische klachten. Het maakt me zenuwachtig. Ik maak giechelend een grapje tegen een vriendin of ze me wel komt bezoeken in de gevangenis met mijn kinderen. Grapje? Shit. Shit. Shit.

\section{Autonomie}

Hij is dankbaar, maar altijd heel formeel. Hij hecht erg aan zijn autonomie. Ik begrijp dat wel en ik mag hem wel. Het is voor hem onvoorstelbaar dat er mensen zijn die in een verpleeghuis kunnen wonen. Stiekem denk ik: heeft u enig idee wat dit met mij doet? Stiekem hoop ik op de erkenning van dit gevoel van hem voor mij. Dat zou me steunen maar die erkenning zal niet komen. Shit. Shit. Shit. Ik doorloop samen met hem en met het verzorgende team netjes het hele protocol. Basisarts erbij, want je moet alles toch een keer meemaken in het leven? Mensen genoeg om mee te praten, maar ik

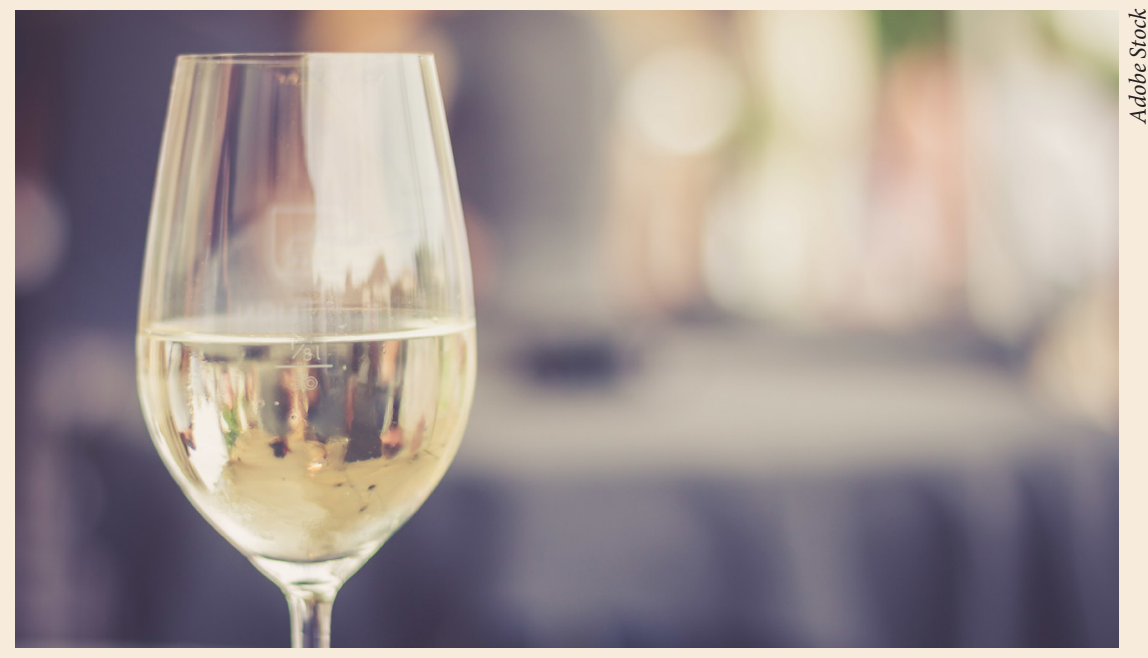

voel me toch heel alleen. De SCEN-arts vindt het invoelbaar en kan meegaan in zijn wens. Het voldoet en ik denk: shit, shit, shit.

Ik prik een datum, maar hij wil graag een paar dagen later, om een reden die ik nogal dubieus vind. Maar ach, ik ben niet diegene die dood zal gaan. De nachten ervoor droom ik van infusen die niet te prikken zijn. Infusen met tien mogelijke aansluitpunten en ik krijg nergens iets aangesloten. Shit. Shit. Shit.

En dan krijg ik een ferme handdruk en dat is dat. Zoon houdt zijn hand vast en alles is al gezegd. Dus is het erg stil. Moet ik nog iets zeggen en wat dan? De heer kennende lijkt het me het beste om maar helemaal niks te zeggen.

Het gaat makkelijk en snel. Familie gaat even roken. Basisarts belt haar vriend in tranen dat ze nu in een kamer zit met een man die net nog heel erg leefde en nu heel erg dood is.

Mag je trouwens een paar slokjes Chardonnay nemen voordat de GGD-arts is geweest? Mag je de boekenbon van 50 euro aannemen die je als alles achter de rug is van zoon krijgt? Weet ik het. Weet jij het? Het was goed, ik voel me goed, maar ook heel erg shit... •
'Ik krijg een ferme handdruk en dat is dat'

Drs. Marjolein E. Steen is specialist ouderengeneeskunde en kaderarts palliatieve zorg bij Topaz. 